\title{
TRAP1 attenuates H9C2 myocardial cell injury induced by extracellular acidification via the inhibition of MPTP opening
}

\author{
LINGXIAO ZHANG $^{1 *}$, LERONG LIU ${ }^{1 *}$, XIA LI $^{1}$, XING ZHANG $^{2}$, JIANGPEI ZHAO $^{3}$, \\ YUANYUAN LUO ${ }^{1}$, XIANGYU GUO $^{4}$ and TONGFENG ZHAO ${ }^{1}$
}

\author{
Departments of ${ }^{1}$ Endocrinology, ${ }^{2}$ Nephrology and ${ }^{3}$ Neurology, The Sixth Affiliated Hospital, Sun Yat-Sen University, \\ Guangzhou, Guangdong 510655; ${ }^{4}$ Guangdong-Hongkong-Macau Institute of CNS Regeneration, \\ Ministry of Education CNS Regeneration Collaborative Joint Laboratory, Jinan University, \\ Guangzhou, Guangdong 510632, P.R. China
}

Received December 8, 2019; Accepted May 14, 2020

DOI: $10.3892 /$ ijmm.2020.4631

\begin{abstract}
Extracellular acidification leads to cardiac dysfunction in numerous diseases. Mitochondrial dysfunction plays an important role in this process. However, the mechanisms through which extracellular acidification induces mitochondrial dysfunction remain unclear. Tumor necrosis factor receptor-associated protein 1 (TRAP1) maintains mitochondrial function and cell viability in tumor and non-tumor cells. In the present study, extracellular acidification was found to induce H9C2 cell apoptosis, mitochondrial dysfunction and TRAP1 expression. The overexpression of TRAP1 attenuated H9C2 cell injury, while the silencing of TRAP1 exacerbated it. Moreover, mitochondrial permeability transition pore (MPTP) opening, which is associated with the mitochondrial apoptotic pathway and cell death, was also increased in acidic medium. The overexpression of TRAP1 inhibited MPTP opening, while the silencing of TRAP1 promoted it. The protective effect of TRAP1 on cardiomyocytes was abolished by the addition of a specific MPTP opening promoter. Similarly, a specific
\end{abstract}

Correspondence to: Professor Tongfeng Zhao, Department of Endocrinology, The Sixth Affiliated Hospital, Sun Yat-Sen University, 26 Erheng Road of Yuancun, Tianhe, Guangzhou, Guangdong 510655, P.R. China

E-mail: ztfzxy71@163.com

*Contributed equally

Abbreviations: TRAP1, tumor necrosis factor receptor-associated protein 1; MPTP, mitochondrial permeability transition pore; MMP, mitochondrial membrane potential; TMRM, tetramethylrhodamine, methyl ester; CCK-8, Cell Counting kit-8; 7-AAD, 7-aminoactinomycin D; APC, allophycocyanin; ROS, reactive oxygen species; MES, 4-morpholineethanesulfonic acid; BSA, bovine serum albumin; C3, caspase-3; CC3, cleaved caspase 3; TEM, transmission electron microscopy

Key words: TNF receptor-associated protein 1, extracellular acidification, cell apoptosis, mitochondrial function, mitochondrial permeability transition pore
MPTP opening inhibitor reversed cell injury by silencing TRAP1. Taken together, the findings of the present study demonstrate that TRAP1 attenuates H9C2 cell injury induced by extracellular acidification by inhibiting MPTP opening.

\section{Introduction}

Extracellular acidosis is a common abnormality of the cellular microenvironment, and can be caused by various pathological states, including hypoxia, ischemia reperfusion, severe infection and renal dysfunction (1). Extracellular acidosis may reduce tissue $\mathrm{pH}$ to 6.5 or even 6.0 (2). Cardiomyocytes are sensitive to extracellular acidosis, since they become prone to apoptosis, which leads to cardiac dysfunction (3-5). Previous studies have indicated that mitochondrial damage caused by extracellular acidosis plays an important role in cell death (6).

Tumor necrosis factor receptor-associated protein 1 (TRAP1) belongs to the heat shock protein 90 family and is located in the mitochondria. It was first identified for its role in anti-oxidative stress and maintaining mitochondrial integrity $(7,8)$. TRAP1 is widely distributed in various types of cells, including cardiomyocytes. Previous studies have demonstrated that the expression of TRAP1 is increased by multiple pathological stimuli, such as hypoxia, ischemia, glucose deprivation and oxidative stress, in order to prevent cell death in vital organs (9-11). However, whether the expression of TRAP1 is protectively increased in cardiomyocytes under extracellular acidosis remains unknown $(7,12,13)$.

The present study thus aimed to investigate whether TRAP1 protects cardiomyocytes in acidic medium, and whether mitochondrial permeability transition pore (MPTP) opening is involved in this process.

\section{Materials and methods}

Cell culture and acidosis treatment. Cell culture methods were performed as previously described (14). The rat heart cell line, H9C2, was purchased from Cell Bank of the Chinese Academy of Sciences (cat. no. GNR 5). The cells were cultured in Dulbecco's modified Eagle's medium (DMEM; cat. no. 11965175; Gibco; Thermo Fisher Scientific, Inc.) with high 
glucose supplemented with $10 \%$ fetal bovine serum (BSA; cat. no. 10099141C Gibco; Thermo Fisher Scientific, Inc.) and $1 \%$ penicillin/streptomycin (cat. no. 516106; Sigma-Aldrich; Merck KGaA). After two passages and at 60-70\% confluency, cells were transferred to 96- or 6-well plates or other dishes according to different assays. The $\mathrm{pH}$ of the cell culture medium was adjusted to the desired values $(7.4,7.0,6.5$ or 6.0$)$ using 2-(N-morpholino)ethanesulfonic acid (MES) buffer (cat. no. M8010; Beijing Solarbio Science \& Technology Co., Ltd.).

Western blot analysis. Western blot analysis was conducted as previously described (15). Cell lysates were prepared with radioimmunoprecipitation assay lysis buffer (cat. no. P0013B; Beyotime Institute of Biotechnology) in the presence of a protease inhibitor cocktail (cat. no. CW2200S; Cwbio). Protein concentrations of cell lysates were quantified using a Pierce BCA Protein assay kit (cat. no. 23227; Thermo Fisher Scientific, Inc.). A total of $30 \mu \mathrm{g}$ total proteins were loaded onto each lane and separated via $10 \%$ sodium dodecyl sulfate polyacrylamide gel electrophoresis (SDS-PAGE). After the proteins were transferred to a PVDF membrane (cat. no. IPVH00010; Milipore; Merck KGaA), the membrane were blocked in 5\% non-fat milk (cat. no. P0216; Beyotime Institute of Biotechnology) in TBST (150 mM Tris- $\mathrm{HCl}$, $\mathrm{pH} 7.4,1.5 \mathrm{M} \mathrm{NaCl}, 0.5 \%$ Tween-20) for $1 \mathrm{~h}$ at room temperature, incubated with primary antibodies in blocking solution at $4{ }^{\circ} \mathrm{C}$ overnight, washed with TBST (five times, $5 \mathrm{~min}$ each), incubated with secondary antibodies for $1 \mathrm{~h}$ at room temperature and washed again with TBST (5 times, 5 min each). Antibodies against TRAP1 (1:1,000) and Bcl-2 $(1: 1,000)$ were purchased from Abcam (cat. nos. ab64182 and ab196495, respectively). Antibodies against $\operatorname{Bax}(1: 1,000)$, cleaved caspase-3 $(1: 1,000)$ and caspase-3 $(1: 1,000)$ were purchased from Cell Signaling Technology, Inc. (cat. nos. 5023, 9661 and 9662, respectively). Antibody against GAPDH $(1: 1,000)$ was purchased from ProteinTech Group, Inc. (cat. no. 10494-1-AP). HRP-conjugated secondary antibody $(1: 5,000)$ was obtained from Cwbio (cat. no. CW0103; Cwbio). Bands were visualized by chemiluminescence with Immobilon Western Chemiluminescent HRP Substrate (cat. no. WBKLS; Millipore; Merck KGaA) and ChemiDoc Imaging System (Bio-Rad Laboratories, Inc.). Blots were semi-quantified using ImageJ (v2.1.4.8; National Institute of Health).

Mitochondrial membrane potential (MMP) assay. MMP was detected with tetramethylrhodamine, methyl ester (TMRM; cat. no. I34361; Thermo Fisher Scientific, Inc.) according to the manufacturer's instructions. Briefly, cells were cultured with $50 \mathrm{nmol} / 1 \mathrm{TMRM}$ in serum-free medium at $37^{\circ} \mathrm{C}$ for 30 min, washed with PBS 3 times and then observed under a laser scanning confocal microscope (Leica TCS SP8; Leica Microsystems, Inc.) or analyzed by flow cytometry (FACSCanto II; BD Biosciences).

Cell viability detection. Cell viability was quantified using a Cell Counting kit-8 (CCK-8; cat. no. CK04; Dojindo Molecular Technologies, Inc.) as previously described (16). Cells were seeded into 96-well plates at a density of 2,000 cells per well in complete culture medium. Three replicates were set up for each group. After $24 \mathrm{~h}$, the culture media were changed to DMEM with different $\mathrm{pH}$ values (7.4 and 6.5), and the cells were cultured for the required time according to the corresponding experimental group settings. Subsequently, $10 \mu 1$ CCK-8 was added to each well and incubated for an additional $1.5 \mathrm{~h}$. Optical density values were measured at a 450-nm wavelength on a microplate reader (Multiskan ${ }^{\mathrm{TM}} \mathrm{FC}$; Thermo Fisher Scientific, Inc.).

Cell apoptosis detection. 7-Aminoactinomycin D (7-AAD) and Annexin V-allophycocyanin (APC) flow cytometry assay (cat. no. 70-AP105-100; MultiSciences) were used to detect cell apoptosis according to the manufacturer's instructions. Briefly, cells were incubated in media at different $\mathrm{pH}$ values $(7.4,7.0$, 6.5 and 6.0) for a certain periods of time $(0,2,4,8,12$ and $24 \mathrm{~h})$ and harvested in PBS. The cell pellet was then resuspended in binding buffer and stained with APC-conjugated Annexin V and 7-AAD for $10 \mathrm{~min}$. The cells were then analyzed using a flow cytometer (FACSCanto II; BD Biosciences) and the apoptotic rate of the cells was analyzed using FLOWJO (v10; BD Biosciences).

Recombinant lentivirus vector for TRAPI overexpression and silencing. The recombinant lentivirus vector for the overexpression and silencing of TRAP1 was purchased from GeneCopoeia, Inc. The targeting sequence of the small interfering RNA (siRNA) against rat TRAP1 was 5'-AGA CCAAGGCTACGGATAT-3'. A green fluorescent protein (GFP)-expressing sequence and an anti-puromycin sequence were also constructed into all vectors. The multiplicity of infection in $\mathrm{H} 9 \mathrm{C} 2$ myocardial cells was 10 . As $1 \times 10^{6}$ cells were seeded for transfection, $10^{7} \mathrm{vg}$ lentivirus and $5 \mu \mathrm{g} / \mathrm{ml}$ polybrene (GeneCopoeia, Inc.) were added to the culture medium without fetal bovine serum. At $72 \mathrm{~h}$ post-infection, the cells were selected by puromycin to obtain H9C2 cells stably overexpressing TRAP1 or cells in which TRAP1 was silenced.

Immunofluorescence. Immunofluorescence assay was performed as previously described (17). Cells were seeded and proliferated for $24 \mathrm{~h}$ until $50 \%$ confluence. The cells were then treated with media at different $\mathrm{pH}$ values $(7.4$ and $6.5)$ for the required periods of time $(12 \mathrm{~h})$ and fixed with $4 \%$ paraformaldehyde (cat. no. P0099; Beyotime Institute of Biotechnology) for 15 min. Subsequently, 0.1\% Triton X-100 (cat. no. T9284; Sigma-Aldrich; Merck KGaA) was used for cell permeabilization. The cells were then blocked with $3 \%$ BSA (cat. no. ST023; Beyotime Institute of Biotechnology) for $1 \mathrm{~h}$. After washing with PBS 3 times, a primary anti-TRAP1 rabbit antibody (1:300; cat. no. ab64182; Abcam) was incubated with the cells at $4^{\circ} \mathrm{C}$ overnight, and then a secondary antibody conjugated to Cy3 (1:200; cat. no. 93-6903-250; MultiSciences) was incubated with the cells at room temperature for $1 \mathrm{~h}$. The fluorescence intensity was observed using a laser scanning confocal microscope (Leica TCS SP8; Leica Microsystems, Inc.).

Reactive oxygen species (ROS) assay. Cell ROS levels were detected using CellROS Oxidative Stress Reagents (cat. no. C10443; Thermo Fisher Scientific, Inc.) as previously described (18). The cells were cultured in media with different 
$\mathrm{pH}$ values (7.4 and 6.5) for the corresponding time periods (12 and $24 \mathrm{~h}$ ). The cells were then incubated with serum-free medium containing $5 \mu \mathrm{m}$ CellROX reagent for $30 \mathrm{~min}$ at $37^{\circ} \mathrm{C}$ and washed with PBS 3 times. Subsequently, the cells were analyzed using a flow cytometer (FACSCanto II; BD Biosciences) and FLOWJO (v10; BD Biosciences).

ATP assay. Cell ATP levels were detected using an Enhanced ATP Assay kit (cat. no. S0027; Beyotime Institute of Biotechnology) according to the manufacturer's instructions. Briefly, the cells were cultured in media with different $\mathrm{pH}$ values (7.4 and 6.5) for the corresponding time periods (12 h). Subsequently, every $10^{6}$ cells in different groups were added to $100 \mu \mathrm{l}$ lysis buffer provided with the kit and the cell supernatant was centrifuged at $12,000 \times \mathrm{g}$ for $5 \mathrm{~min}$ at $4^{\circ} \mathrm{C}$ to remove cell debris. A total of $10 \mu \mathrm{l}$ of supernant was then mixed with $100 \mu \mathrm{l}$ of ATP detection solution diluted 4 times with dilution buffer and the luminescence was measured using a luminometer (Varioskan Flash; Thermo Fisher Scientific, Inc.). The luminescence values of ATP standards were determined in a similar manner. The ATP concentration was calculated according to an ATP-standard curve and normalized to protein concentration of the supernatant.

Transmission electron microscopy. The mitochondrial ultrastructure were observed using a transmission electron microscope (Transmission Electron Microscope HT7700; Hitachi). H9C2 cells were collected and fixed in 4\% glutaraldehyde for $1 \mathrm{~h}$ at room temperature and left at $4^{\circ} \mathrm{C}$ overnight. The samples were dehydrated through a graded ethanol series, then incubated in $100 \%$ ethanol and propylene oxide as well as 2 exchanges of pure propylene oxide. Samples were embedded in epoxy resin and polymerized at $60^{\circ} \mathrm{C}$ for $48 \mathrm{~h}$. Specimens were cut into 70-80-nm ultra-thin sections, then mounted on 300-mesh copper grids. Sections were stained with uranyl acetate and leas citrate, then subjected to observation.

Detection of MPTP opening. The MPTP opening of the H9C2 cells was detected using a MitoProbe Transition Pore assay kit (cat. no. M34153; Thermo Fisher Scientific, Inc.) according to the manufacturer's instructions. Briefly, cells were seeded in a 6-well plate (cat. no. 354773; Corning Inc.) and cultured in media with different $\mathrm{pH}$ values (7.4 and 6.5) for the required time period $(12 \mathrm{~h}$ ) after reaching $50-60 \%$ confluence. The cells were then collected and resuspended in Hanks' Balanced Salt Solution (HBSS)/Ca buffer. Subsequently, $5 \mu$ l Calcein AM working buffer (cat. no. M34153; Thermo Fisher Scientific, Inc.) and $\mathrm{CoCl}_{2}$ were added to the cell suspension solution, which was subsequently incubated for $30 \mathrm{~min}$ at $37^{\circ} \mathrm{C}$. After staining, the samples were analyzed using a flow cytometer (FACSCanto II; BD Biosciences) with 488-nm excitation and 517-nm emission wavelengths and FLOWJO (v10; BD Biosciences).

Chemical reagents. Mitochondrial permeabolity transition pore (MPTP) opening inhibitor, cyclosporin A (cat. no. HY-B0579; MedChemExpress), was used to inhibit MPTP opening (19). And MPTP opening promoter, atractyloside (cat. no. HY-N0237; MedChemExpress), was used to promote MPTP opening (20). Briefly, $5 \mathrm{mg}$ cyclosporin
A powder were dissolved in $0.4158 \mathrm{ml}$ dimethyl sulfoxide (DMSO) to prepare stock solutions $(10 \mathrm{mM})$. A total of $5 \mathrm{mg}$ atractyloside power was dissolved in $1.1148 \mathrm{ml}$ DMSO to prepare a stock solution $(10 \mathrm{mM})$. Subsequently, $1 \mu 1$ stock solution (cyclosporin A or atractyloside respectively) was added to $1 \mathrm{ml}$ culture medium ( $\mathrm{pH}$ 6.5) as a working solution $(10 \mu \mathrm{M})$, and the cells were then cultured for $12 \mathrm{~h}$, respectively.

Statistical analysis. Data represent the means \pm SD from 3 independent experiments and were analyzed using SPSS v25.0 (IBM Corp.). The Student's t-test was used to analyze the results of CCK-8 assay at each time point between the 2 groups in Fig. 1C. One-way analysis of variance followed by Tukey's post hoc test was carried out to measure differences between groups. $\mathrm{P}<0.05$ was considered to indicate a statistically significant difference.

\section{Results}

Extracellular acidification induces H9C2 cell apoptosis, decreases cell viability and causes mitochondrial dysfunction. To investigate whether metabolic acidosis induces cell apoptosis and decreases cell viability, CCK-8 assay and Annexin V-APC/7-AAD apoptosis kit were used. The results revealed that $\mathrm{H} 9 \mathrm{C} 2$ cell apoptosis was increased in lower $\mathrm{pH}$ culture medium ( $\mathrm{pH} 6.5$ or 6.0 ) or longer acidic culture time (Fig. 1A and B), and cell viability decreased in acidic medium (Fig. 1C). The MMP of the H9C2 cells was also decreased in acidic medium, which indicated that mitochondrial function was damaged (Fig. 1D).

Extracellular acidification increases TRAP1 expression in H9C2 cells. Western blot analysis and immunofluorescence were used to detect the expression of TRAP1 in acidic medium. The results of western blot analysis revealed that the expression of TRAP1 increased after $4 \mathrm{~h}$ in acidic medium (Fig. 2A and B). Immunofluorescence assay also demonstrated that the acidic environment increased the expression of TRAP1 (Fig. 2C).

TRAPl inhibits acid-induced H9C2 cell apoptosis and increases cell viability. Considering the increase observed in TRAP1 expression in acidic medium, the present study aimed to confirm that TRAP1 is a protective factor for H9C2 cells in acidic medium. TRAP1-GFP lentiviral vector was constructed for TRAP1 overexpression (ov-TRAP1) or TRAP1 silencing (sh-TRAP1). At 5 days post-transfection, H9C2 cells expressing a high level of green fluorescence were observed (Fig. 3A). The results of western blot analysis further confirmed that the expression of TRAP1 was significantly increased by Lenti-TRAP1 and decreased by Lenti-TRAP1 siRNA (Fig. 3B). Following culture in acidic medium for 12 or $24 \mathrm{~h}$, TRAP1 overexpression inhibited H9C2 cell apoptosis (Fig. 3C and D) and increased cell viability (Fig. 3E) in acidic medium, while TRAP1 silencing aggravated the damage to the cells induced by acidic medium (Fig. 3C and E).

TRAP1 reverses the acid-induced mitochondrial dysfunction of H9C2 cells. H9C2 cell mitochondrial function was detected by ATP assay and MMP assay. The results revealed that the 
A

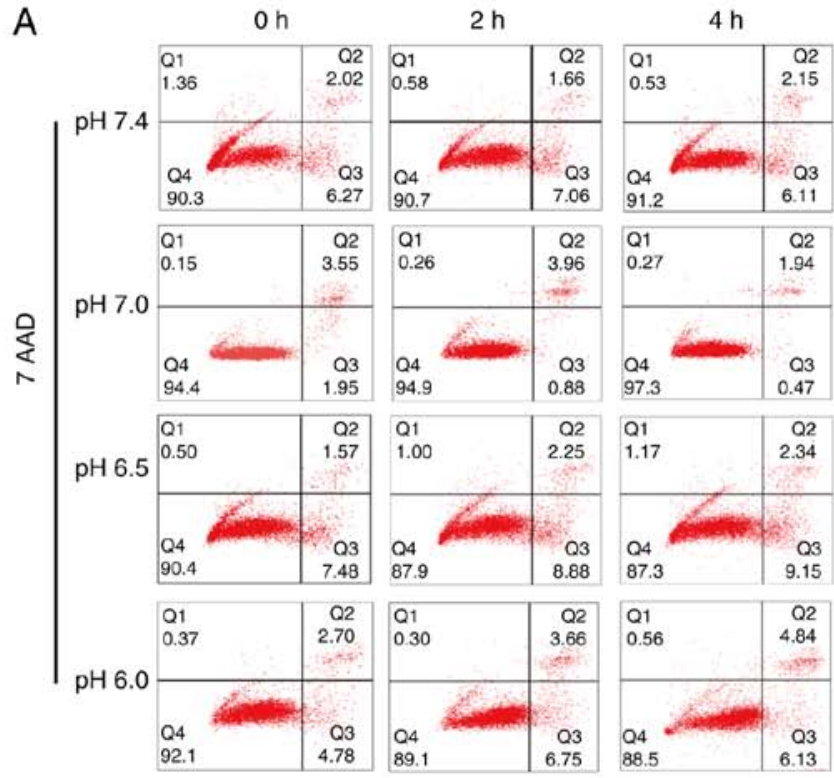

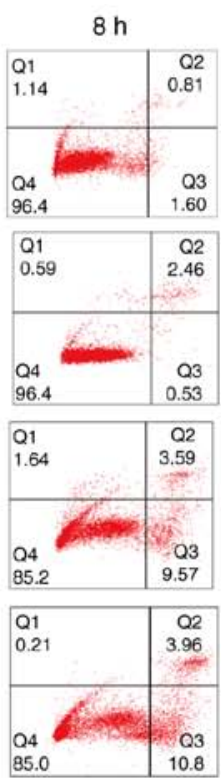
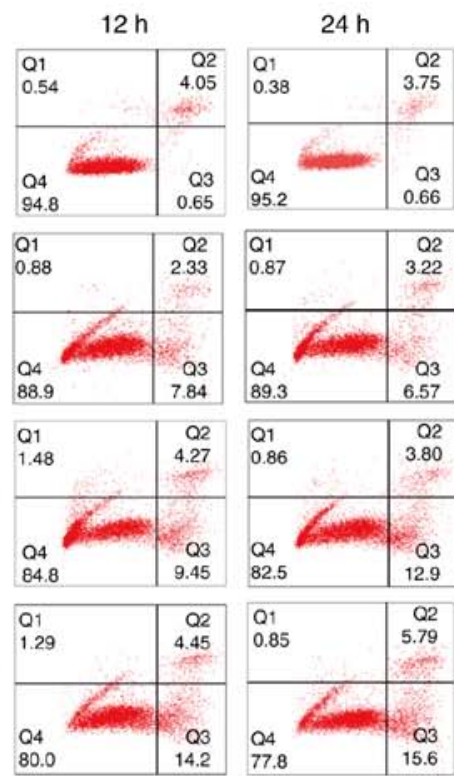

80.0

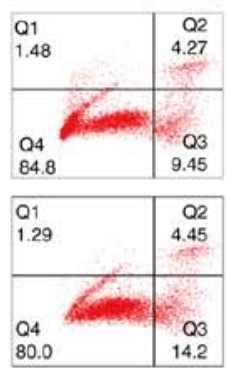

APC
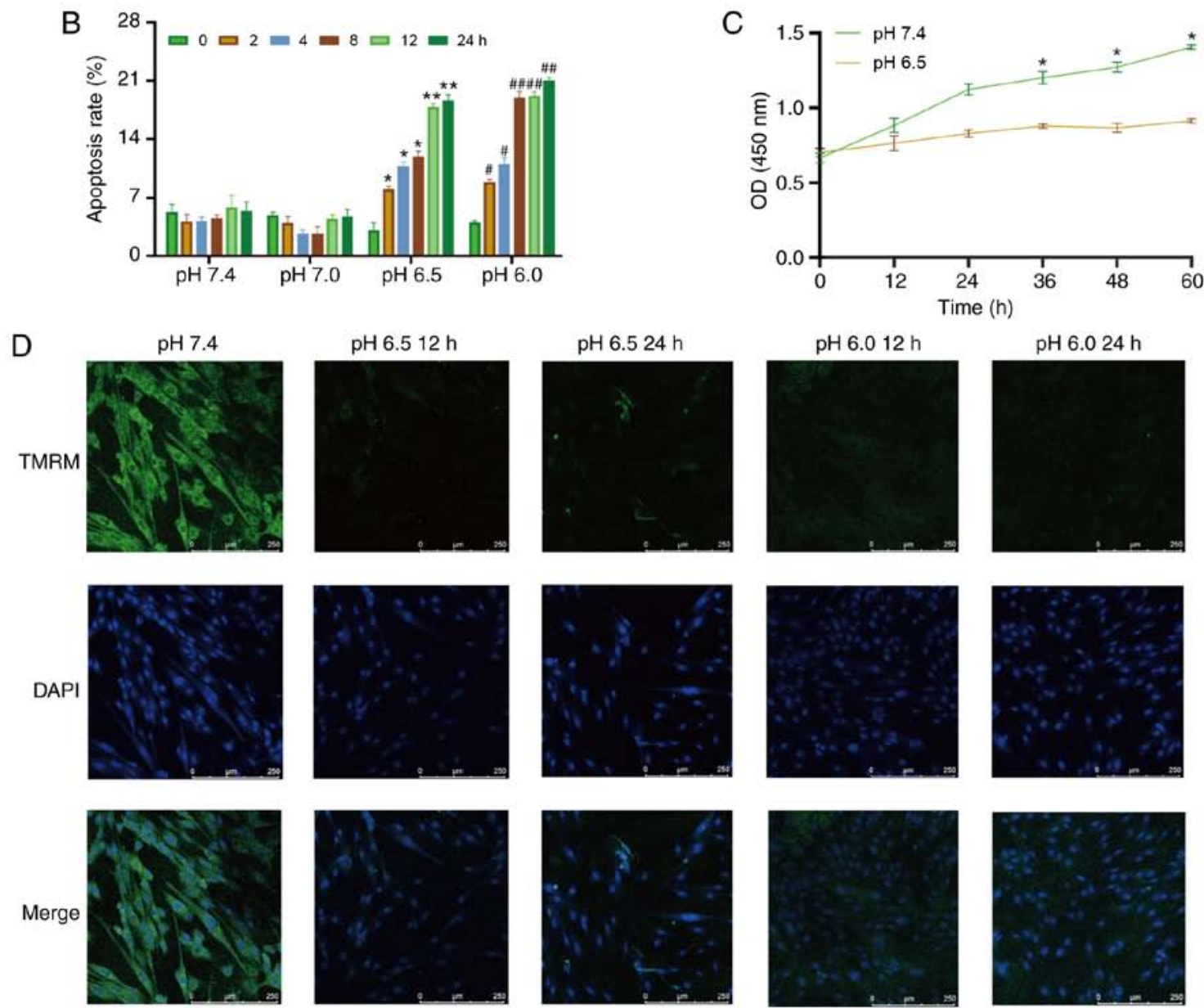

Figure 1. Extracellular acidification induces H9C2 cell apoptosis and decreases MMP. (A) H9C2 cell apoptosis induced by extracellular acidification. H9C2 cells were cultured in different $\mathrm{pH}$ media (7.4, 7.0, 6.5 and 6.0) for 0, 2, 4, 8, 128 or $24 \mathrm{~h}$. (B) Quantitative analysis of the results shown in (A). (C) CCK-8 assay of $\mathrm{H} 9 \mathrm{C} 2$ cells in different $\mathrm{pH}$ media. (D) MMP of $\mathrm{H} 9 \mathrm{C} 2$ cells in different $\mathrm{pH}$ media. TMRM (green) is a type of mitochondrial dye, and the fluorescence intensity is positively associated with the cell MMP. Original magnification, $\mathrm{x} 100 .{ }^{*} \mathrm{P}<0.05$ and ${ }^{\# \#} \mathrm{P}<0.01$ vs. 0 h group. ${ }^{*} \mathrm{P}<0.05$ and ${ }^{* * *} \mathrm{P}<0.01$ vs. $\mathrm{pH} 7.4$ group. MMP, mitochondrial membrane potential; TMRM, tetramethylrhodamine, methyl ester.

H9C2 cell MMP (Fig. 4A and B) and ATP levels (Fig. 4D) in acidic medium were significantly lower than those in the cells in neutral $\mathrm{pH}$ medium. TRAP1 overexpression reverse the decrease in MMP and the ATP level induced by acidic medium (Fig. 4A, B and D). However, the levels of ROS were not markedly altered (Fig. 4E). 
A
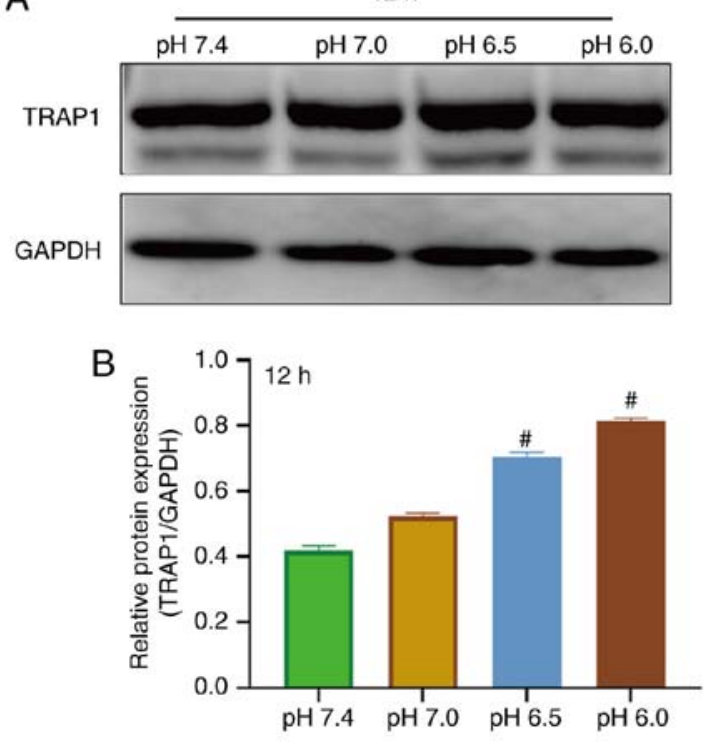
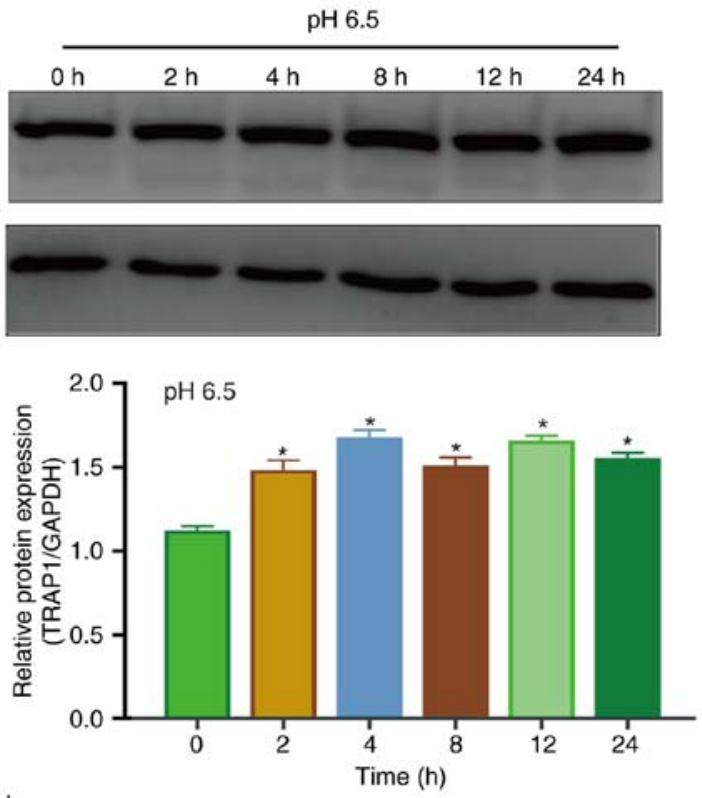

C
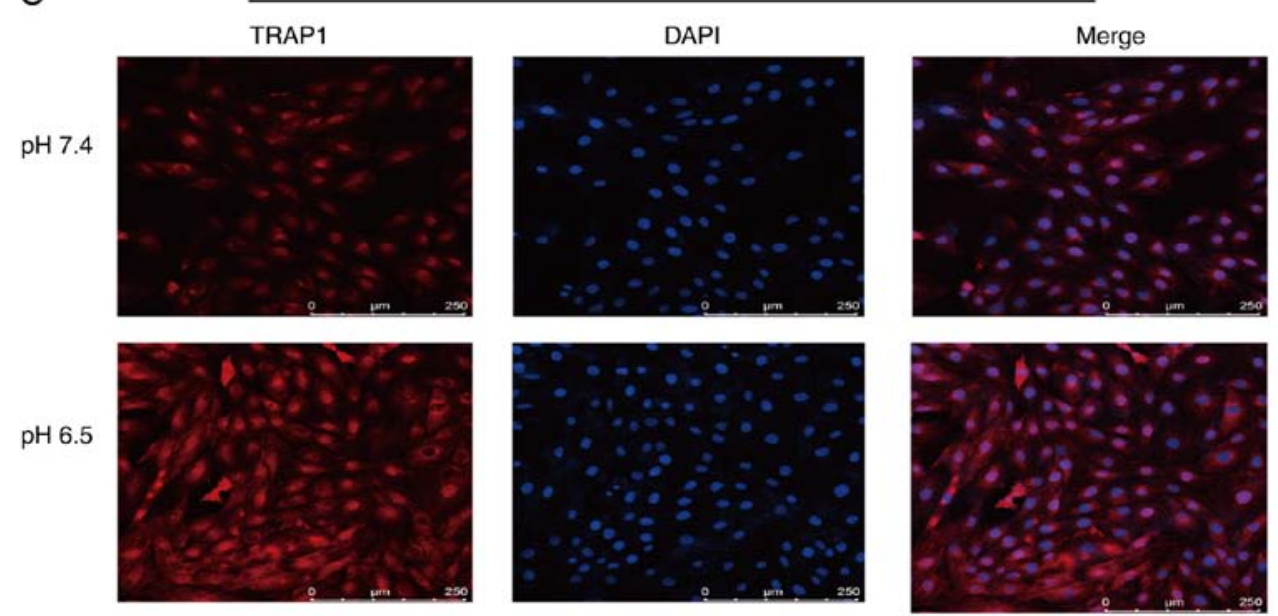

Figure 2. Extracellular acidification increases TRAP1 expression. (A) Western blot analysis of TRAP1 at different pH values for $12 \mathrm{~h}$ or at $\mathrm{pH} 6.5$ for different time periods. (B) Semi-quantitative analysis of the results shown in (A). (C) Immunofluorescence of TRAP1 at different pH values for $12 \mathrm{~h}$. Original magnification, $\mathrm{x} 100 .{ }^{*} \mathrm{P}<0.01$ vs. $\mathrm{pH} 7.4$ group. ${ }^{*} \mathrm{P}<0.05$ vs. 0 h group. TRAP1, tumor necrosis factor receptor-associated protein 1.

TRAPI inhibits the acid-induced mitochondrial apoptotic pathway and maintained normal mitochondrial ultrastructure of $\mathrm{H} 9 \mathrm{C} 2$ cells. The mitochondrial apoptotic pathway is an important pathway of cell apoptosis and is activated following mitochondrial injury. The pro-apoptotic factor, Bax, and the anti-apoptotic factor, Bcl-2, are currently recognized as important components of the mitochondrial apoptotic pathway. They activate caspase-3 (forming cleaved caspase-3) to regulate mitochondrial apoptosis and eventually lead to cell apoptosis. The present study demonstrated that the expression levels of Bax and Bcl-2 increased under extracellular acidification, and the levels of cleaved caspase- 3 exhibited a similar trend (Fig. 4F). TRAP1 overexpression significantly inhibited the expression of Bax and cleaved caspase-3, and maintained the $\mathrm{Bax} / \mathrm{Bcl}-2$ ratio (Fig. 4F). The mitochondrial ultrastructure of $\mathrm{H} 9 \mathrm{C} 2$ cells was severely damaged under extracellular acidification, including the reduction of mitochondrial cristae and mitochondrial vacuolization. TRAP1 overexpression significantly reversed the damage to the normal ultrastructure of the mitochondria (Fig. 4G).
TRAP1 inhibits the MPTP opening of H9C2 cells in acidic medium. The MPTP is an important component of the mitochondrial membrane and is an initiator of the mitochondrial apoptotic pathway. Thus, the present study aimed to investigate the effects of TRAP1 on MPTP opening. The results revealed that the MPTP opening of $\mathrm{H} 9 \mathrm{C} 2$ cells was increased in acidic medium compared with normal pH medium (Fig. 5). The overexpression of TRAP1 decreased MPTP opening, while the silencing of TRAP1 further increased MPTP opening (Fig. 5).

TRAP1 inhibits the mitochondrial apoptotic pathway, stabilizes mitochondrial function, and thus inhibits apoptosis, via the inhibition of MPTP opening. After identifying that TRAP1 decreased acid-induced MPTP opening, atractyloside (Atr, $10 \mu \mathrm{M}$, a specific MPTP opening promoter) and cyclosporin A (CysA, $10 \mu \mathrm{M}$, a specific MPTP opening inhibitor) were used to further identify whether TRAP1 protects $\mathrm{H} 9 \mathrm{C} 2$ cells in acidic medium by inhibiting MPTP opening. It was observed that the MPTP opening promoter abolished the 
A

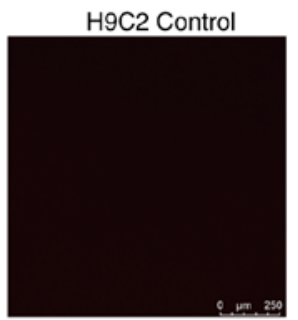

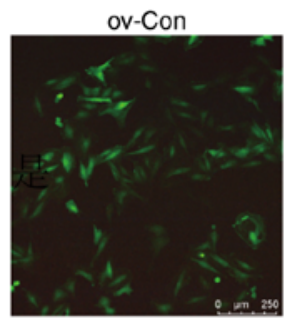
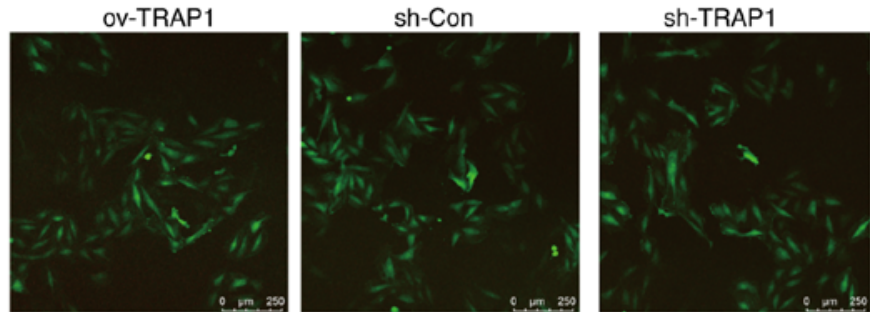

B

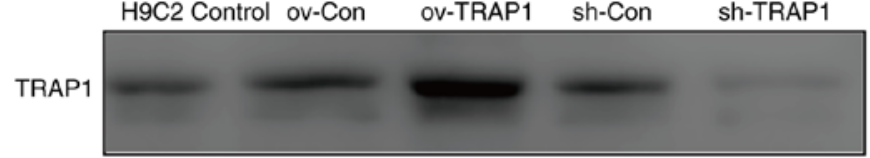

GAPDH
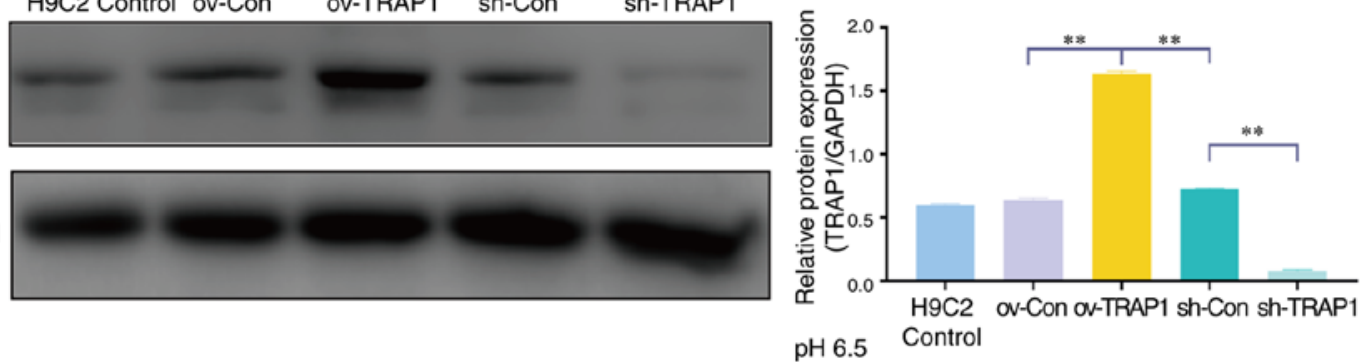

C
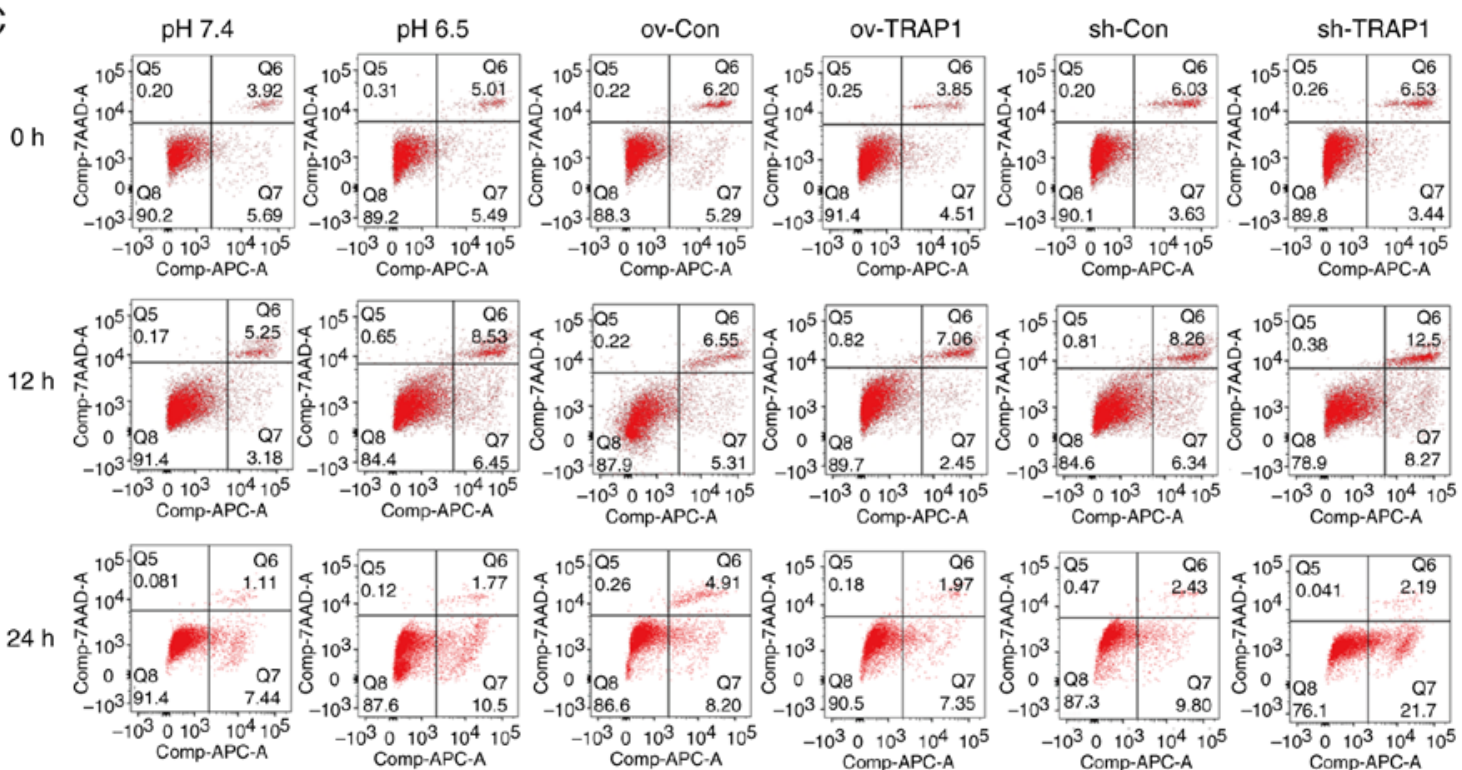

D
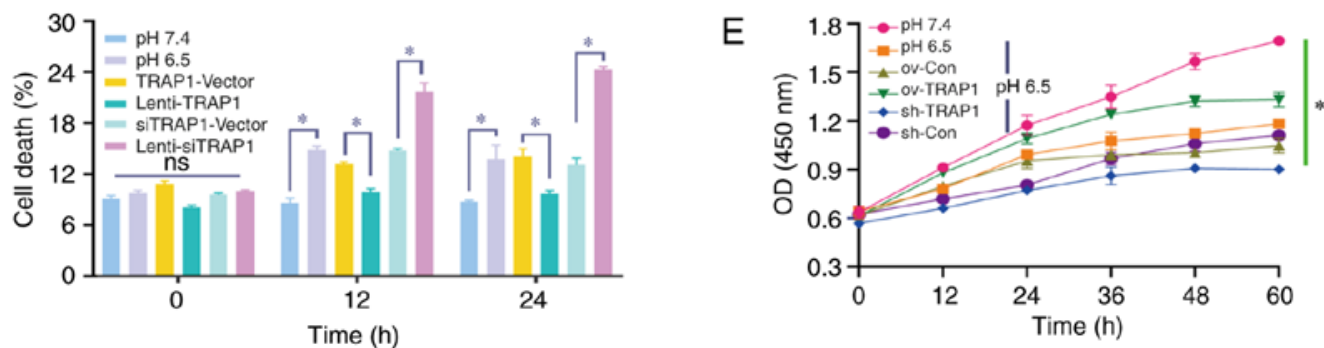

Figure 3. TRAP1 inhibits H9C2 cell apoptosis induced by extracellular acidification. (A) GFP expression of H9C2 cells after 5 days of transfection. Original magnification, x100. (B) Western blot analysis of TRAP1 to identify transfection efficiency. (C) H9C2 cell apoptosis induced by extracellular acidification after transfection. (D) Quantitative analysis of the results shown in (C). (E) CCK-8 assay of $\mathrm{H} 9 \mathrm{C} 2$ cells in acidic medium following transfection. ${ }^{*} \mathrm{P}<0.05$ and ${ }^{* *} \mathrm{P}<0.01$. ov-Con, H9C2 cells transfected with vector; ov-TRAP1, H9C2 cells overexpressing TRAP1; sh-Con, H9C2 cells transfected with scrambled siRNA; sh-TRAP1, H9C2 cells transfected with siRNA; TRAP1, tumor necrosis factor receptor-associated protein 1.

protective effects of TRAP1 on H9C2 cells (Fig. 6A and C-F). On the other hand, the MPTP opening inhibitor reversed the increased expression of Bax, caspase-3 and cleaved caspase-3, further reversing mitochondrial dysfunction and cell apoptosis induced by the silencing of TRAP1 (Fig. 6A and C-F). The normal mitochondrial ultrastructure maintained by TRAP1 overexpression was abolished following Atr treatment.
Unexpectedly, it was not observed that CysA significantly reversed the mitochondrial ultrastructure damage induced by TRAP1 silencing, which may indicate that TRAP1 maintained mitochondrial ultrastructure in a mPTP-independent manner (Fig. 6G). On the whole, TRAP1 protected mitochondrial function and attenuated cell apoptosis under extracellular acidification via the inhibition of MPTP opening (Fig. 7). 
A

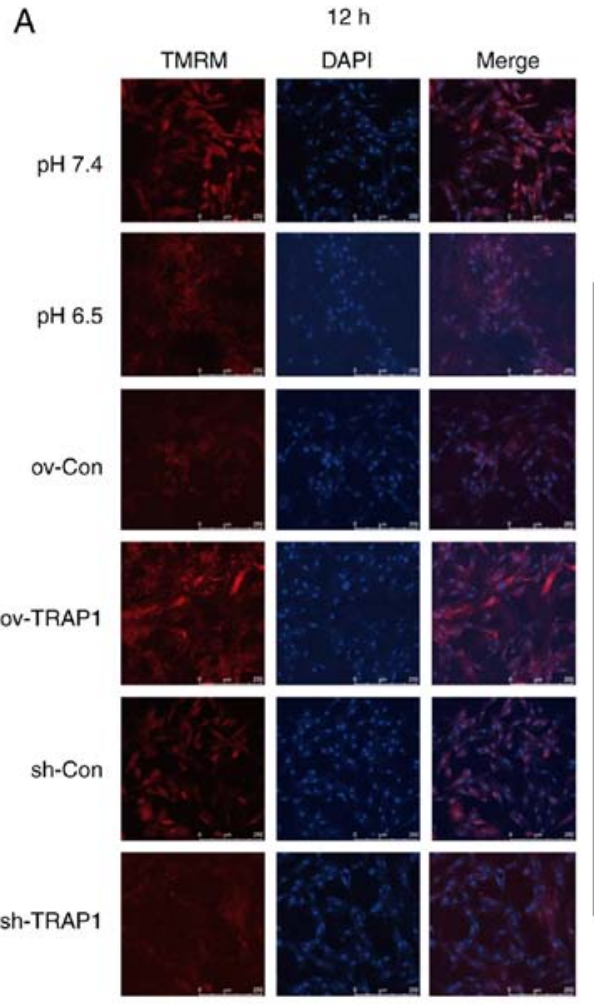

E
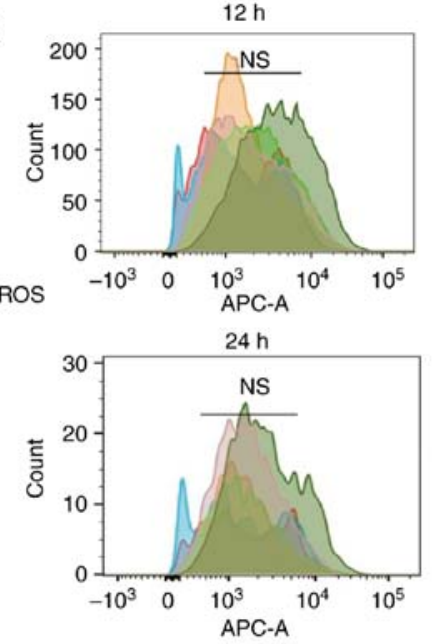

B

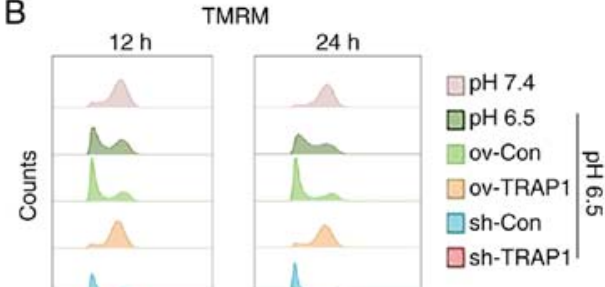

$\mathrm{pH} 6.5$
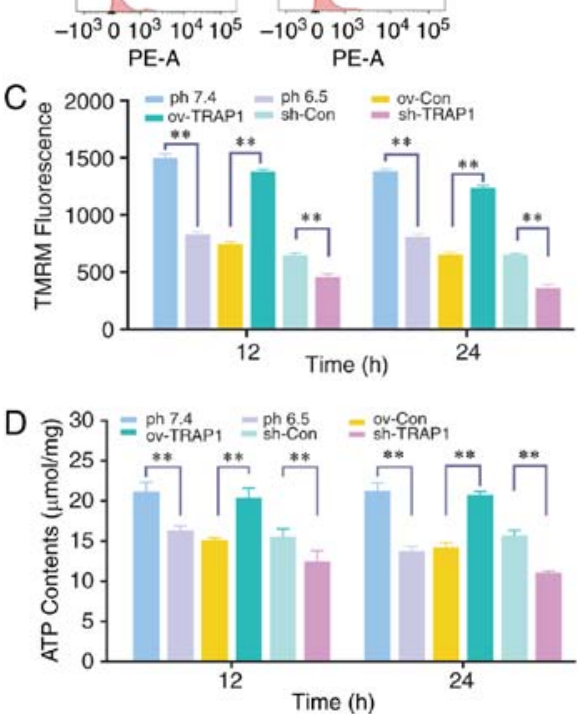

$\mathrm{F}$

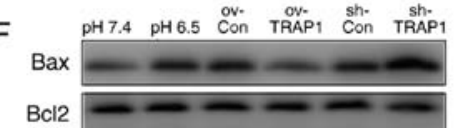

C3

CC3

GAPDH $=-2$

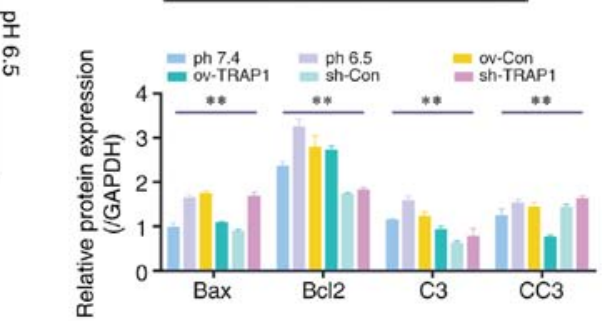

pH $6.512 \mathrm{~h}$

G

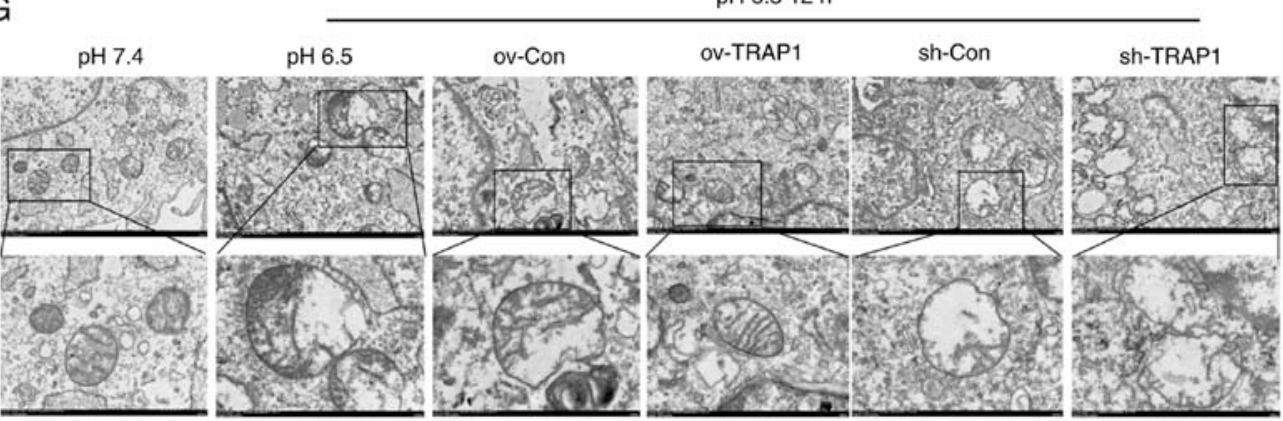

Figure 4. Effect of the overexpression or silencing of TRAP1 on the mitochondrial function. (A) MMP of H9C2 cells in pH 6.5 at $12 \mathrm{~h}$ following transfection. TMRM (red) is a type of mitochondrial dye, and the fluorescence intensity is positively associated with the cell MMP. Original magnification, $\mathrm{x} 100$. (B) MMP of $\mathrm{H} 9 \mathrm{C} 2$ cells detected using a flow cytometer. After staining cells for 45 min with TMRM, the fluorescence intensity was detected by flow cytometry. (C) Quantitative analysis of the results shown in (B). (D) ATP levels of H9C2 cells in pH 6.5 at $12 \mathrm{~h}$ post-transfection. (E) ROS levels of H9C2 cells in pH 6.5 at $12 \mathrm{~h}$ following transfection. (F) Western blot analysis of Bax, Bcl-2, caspase-3 and cleaved caspase-3, and semiquantitative analysis of the protein levels. (G) Mitochondrial ultrastructure of $\mathrm{H} 9 \mathrm{C} 2$ cells was severely damaged under extracellular acidification, including the reduction of mitochondrial cristae and mitochondrial vacuolization. TRAP1 overexpression significantly reversed the damage to the normal ultrastructure of the mitochondria. ${ }^{* *} \mathrm{P}<0.01$. ov-Con, H9C2 cells transfected with vector; ov-TRAP1, H9C2 cells overexpressing TRAP1; sh-Con, H9C2 cells transfected with scrambled siRNA; sh-TRAP1, H9C2 cells transfected with siRNA; C3, caspase-3; CC3, cleaved caspase-3; TRAP1, tumor necrosis factor receptor-associated protein 1. 

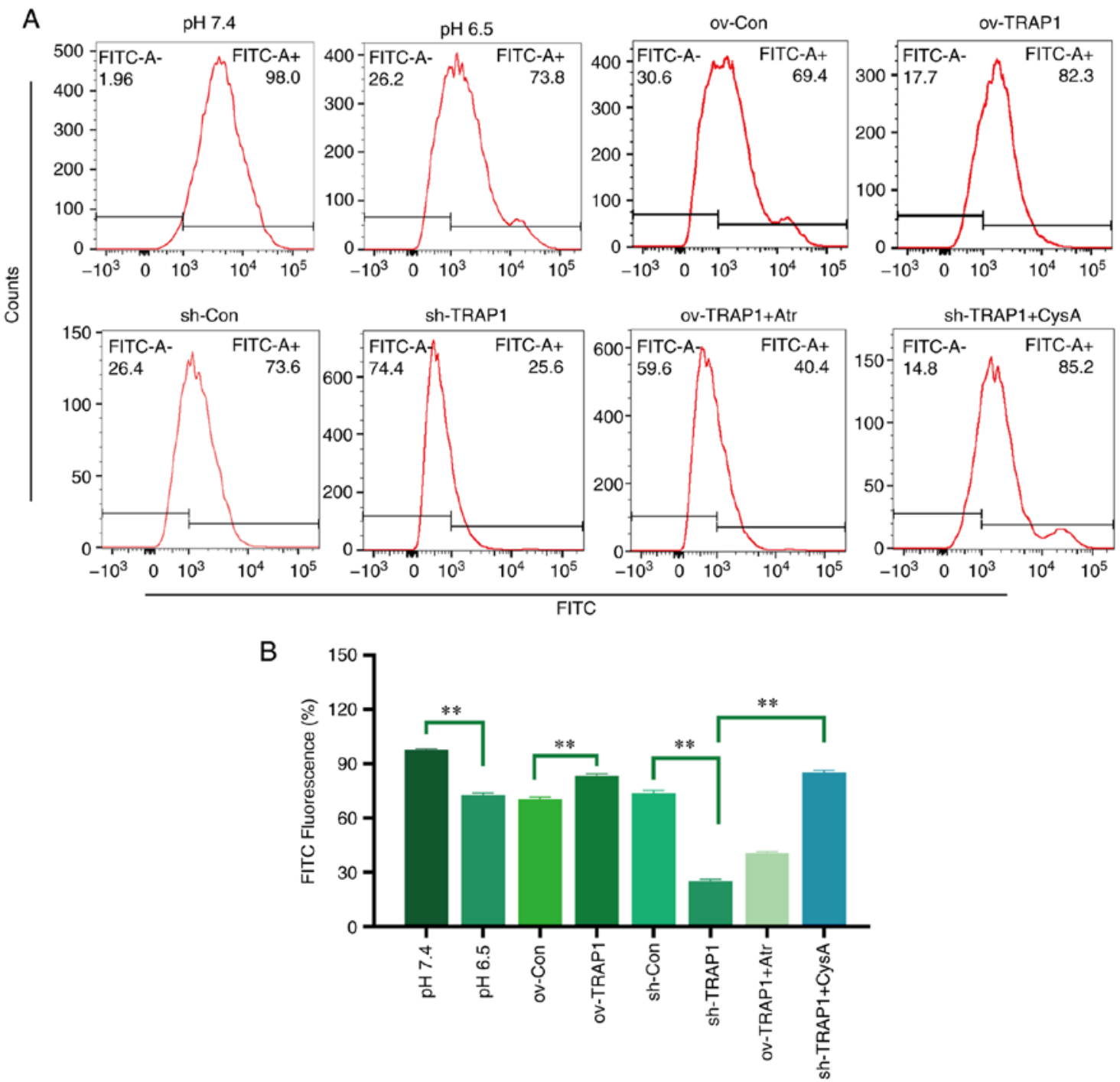

Figure 5. Effect of TRAP1 on MPTP opening. (A) MPTP opening was detected using a flow cytometer. The fluorescence intensity was negatively associated with MPTP opening. (B) Quantitative analysis of the results shown in (A). ${ }^{* *} \mathrm{P}<0.01$. ov-Con, H9C2 cells transfected with vector; ov-TRAP1, H9C2 cells overexpressing TRAP1; sh-Con, H9C2 cells transfected with scrambled siRNA; sh-TRAP1, H9C2 cells transfected with TRAP1-siRNA; ov-TRAP1 + Atr, H9C2 cells overexpressing TRAP1 after adding Atr $(10 \mu \mathrm{M})$ to the culture medium; sh-TRAP1 + CysA, H9C2 cells transfected with TRAP1-siRNA in the presence of CysA $(10 \mu \mathrm{M})$ in the culture medium; TRAP1, tumor necrosis factor receptor-associated protein 1.

\section{Discussion}

The present study firstly reported that extracellular acidosis increased the expression of TRAP1 in H9C2 cells, which is parallel to other pathological models such as hypoxia or ischemia reperfusion injury (21-23). Subsequently, lentiviral vectors were used to overexpress and silence TRAP1 in H9C2 cells. The overexpression of TRAP1 inhibited cell apoptosis and increased cell viability, whereas the silencing of TRAP1 deteriorated the cell damage induced by extracellular acidosis. These results demonstrate that TRAP1 protects $\mathrm{H} 9 \mathrm{C} 2$ cells in extracellular acidosis, which enhances the protective effects of TRAP1 against cell injury $(11,13,24)$.

TRAP1 has been reported to maintain MMP and cell ATP production efficiency, and inhibit cell ROS, thus protecting cells under pathological conditions $(22,25)$. Zhang et al used siRNA to silence TRAP1 expression in $\mathrm{H} 9 \mathrm{C} 2$ cells, observing that mitochondrial function was deteriorated in high glucose medium (26). Consistent with the findings of previous studies, the present study observed that the overexpression of TRAP1 maintained MMP and the cellular ATP level, while the silencing of TRAP1 decreased MMP and the cellular ATP level. Severe mitochondrial damage activates the mitochondrial apoptotic pathway and induces cell apoptosis. The findings of the present study demonstrated that extracellular acidosis activated the cell mitochondrial apoptotic pathway, while the overexpression of TRAP1 inhibited this activation. These results strongly indicate that TRAP1 protects the physiological function of the mitochondria under conditions of extracellular acidosis, and inhibits the activation of the mitochondrial apoptotic pathway, thus preventing cell death. Furthermore, TRAP1 overexpression can maintain the normal mitochondrial ultrastructure, while TRAP1 silencing leads to further damage to the ultrastructure. This indicates that TRAP1 protects both mitochondrial function and morphology under conditions of extracellular acidification. Moreover, the present study did not detect any increase in cell ROS levels during extracellular acidosis. The association between ROS 
A

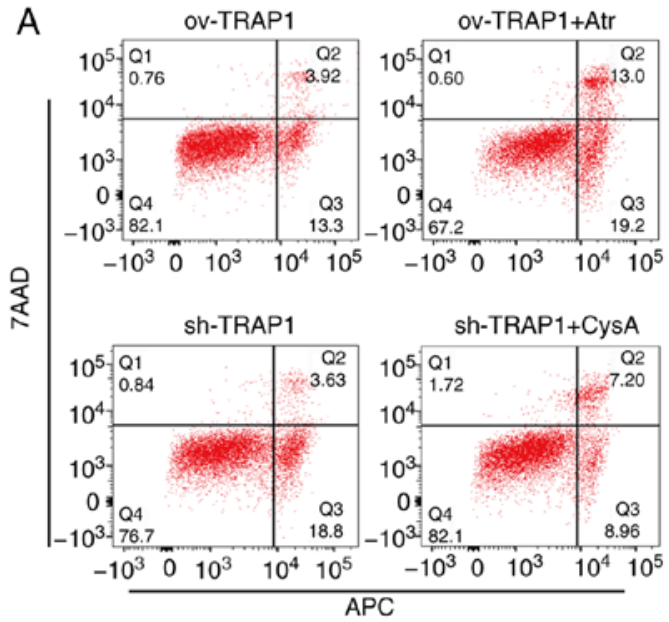

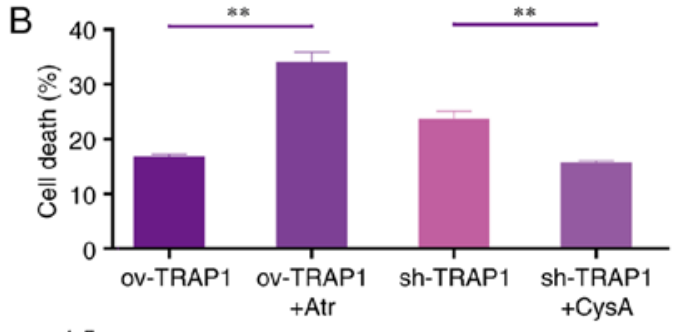

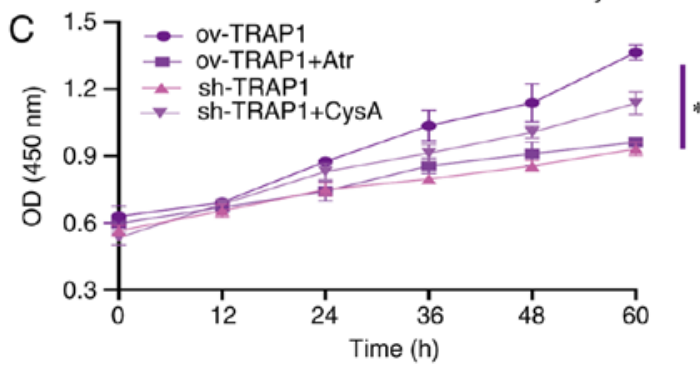

D
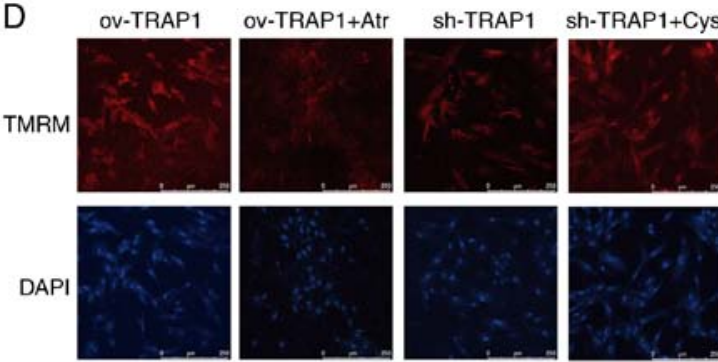

$\mathrm{E}$ ov-TRAP1 $=$ ov-TRAP1+Atr
sh-TRAP1
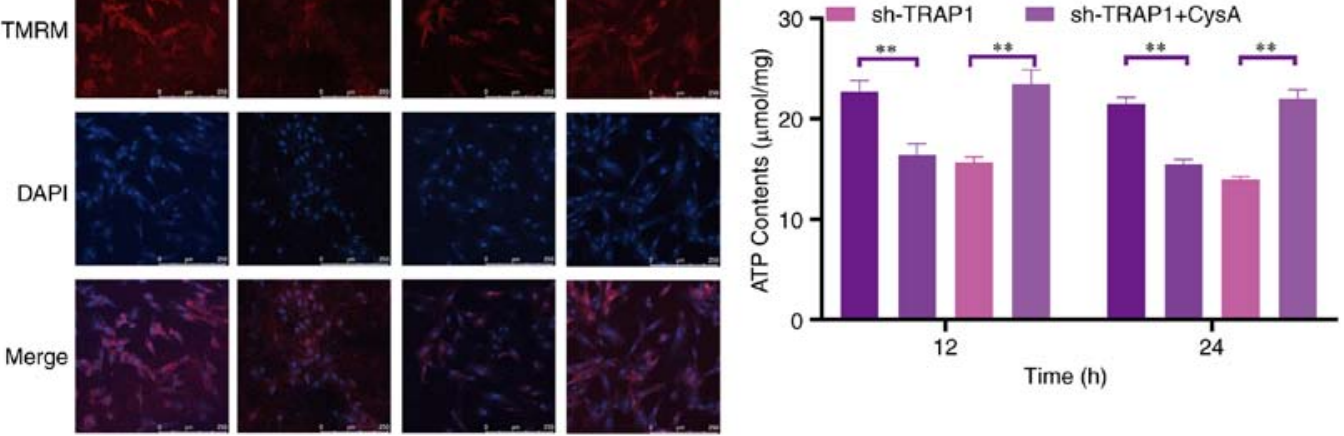

F
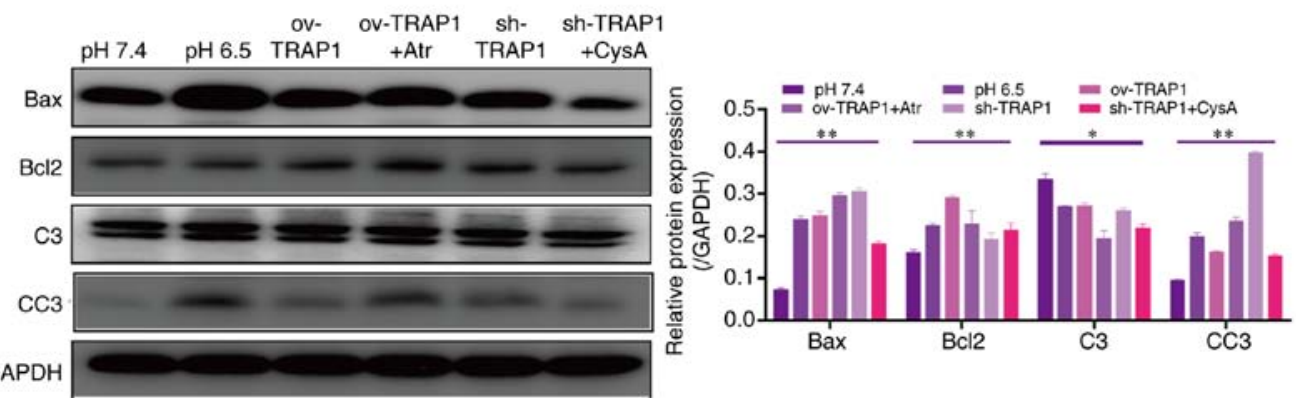

G
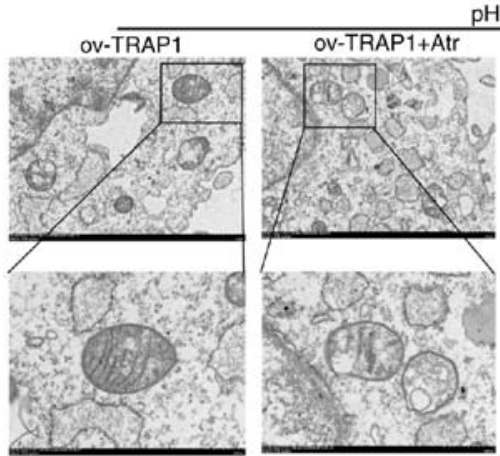

$\mathrm{pH} 6.512 \mathrm{~h}$
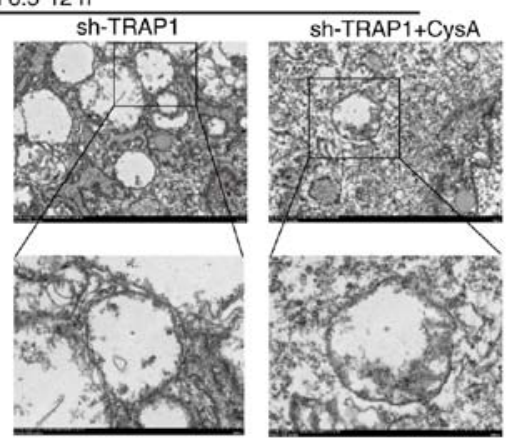

Figure 6. TRAP1 protects H9C2 cells in acidic medium by inhibiting MPTP. (A) H9C2 cell apoptosis induced by extracellular acidification after transfection and addition of drugs. (B) MMP of $\mathrm{H} 9 \mathrm{C} 2$ cells in $\mathrm{pH} 6.5$ for $12 \mathrm{~h}$ after transfection. TMRM (red) is a type of mitochondrial dye, and the fluorescence intensity is positively associated with the cell MMP. (C) CCK-8 assay of H9C2 cells in acidic medium following transfection and addition of drugs. (D) MMP of H9C2 cells was detected using a flow cytometer. After staining the cells for $45 \mathrm{~min}$ with TMRM, the fluorescence intensity was detected by flow cytometry. Original magnification, x100. (E) ATP levels of $\mathrm{H} 9 \mathrm{C} 2$ cells in $\mathrm{pH} 6.5$ and $12 \mathrm{~h}$ following transfection and the addition of drugs. (F) Western blot analysis of Bax, Bcl-2, caspase-3 and cleaved caspase-3, and semi-quantitative analysis of the protein levels. (G) Mitochondrial ultrastructure of the cells following transfection with sh-TRAP1 and CysA. ${ }^{*} \mathrm{P}<0.05$ and ${ }^{* *} \mathrm{P}<0.01$. ov-TRAP1, H9C2 cells overexpressing TRAP1; sh-TRAP1, H9C2 cells transfected with TRAP1-siRNA; ov-TRAP1 + Atr, H9C2 cells overexpressing TRAP1 after adding Atr $(10 \mu \mathrm{M})$ to the culture medium; sh-TRAP1 + CysA, H9C2 cells transfected with TRAP1-siRNA after adding CysA $(10 \mu \mathrm{M})$ to the culture medium; $\mathrm{C} 3$, caspase-3; CC3, cleaved caspase-3; TRAP1, tumor necrosis factor receptor-associated protein 1. 


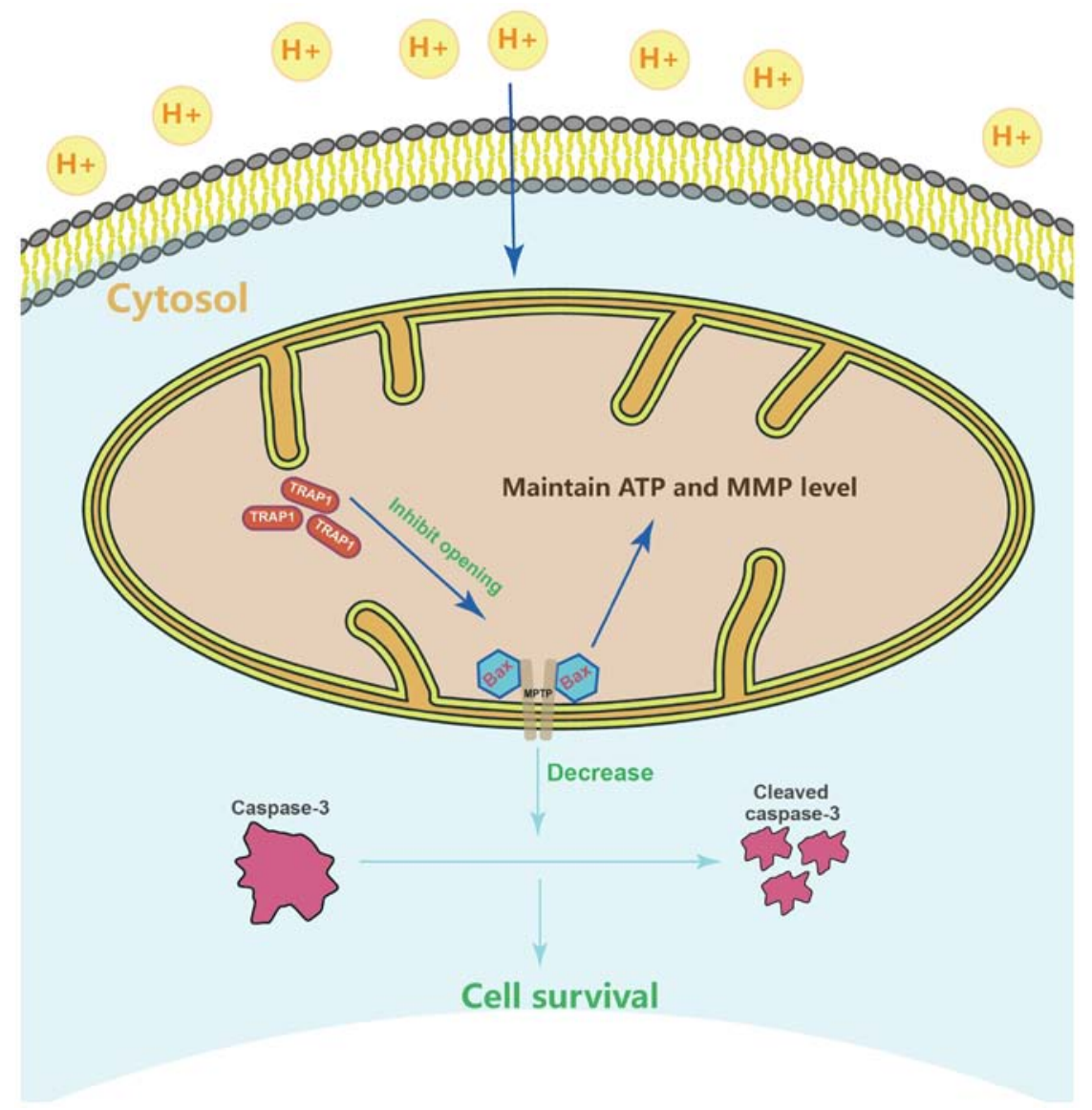

Figure 7. Schematic diagram depicting the protection mechanisms of TRAP1 in H9C2 cells under conditions of extracellular acidification. TRAP1 inhibits acid-induced MPTP opening and the expression or activation of apoptosis protein to protect mitochondrial function, which attenuates H9C2 cell injury and apoptosis under conditions of extracellular acidification. TRAP1, tumor necrosis factor receptor-associated protein 1.

and extracellular acidosis remains controversial. Previous studies have suggested that there is a positive association. Teixeira et al reported that extracellular acidification increases cell ROS level and induces protein carbonylation (27). However, few studies, such as the one by Wang et al have reported that extracellular acidification directly reconstructs acid-sensing ion channel 1a (ASIC1a) conformation to induce cell injury, which was different from the ROS-dependent cell injury pathological model, including hypoxia or ischemia reperfusion injury (28). These results suggest that extracellular acidosis may exert a ROS-independent effect on cell damage. These results confirmed this hypothesis. Moreover, different pathological processes may be involved in different disease models may involve, which leads to different phenotypes. Therefore, the association between extracellular acidification and ROS warrants further investigation.

Furthermore, the present study identified the mechanisms underlying the protective effects of TRAP1 on mitochondrial function under conditions of extracellular acidosis. MPTP is an important channel protein across the mitochondrial inner and outer membranes (29-31). Previous studies have identified that MPTP opening is a key step to induce cell mitochondrial damage and activates the mitochondrial apoptotic pathway (32-34). The present study revealed that extracellular acidosis increased MPTP opening, while the overexpression of TRAP1 reversed this effect. The addition of the specific MPTP opening promoter, Atr, to increase MPTP opening, abolished the protective effects of
TRAP1. The specific MPTP opening inhibitor, CysA, alleviated cell injury and inhibited the mitochondrial apoptotic pathway in acidic medium when TRAP1 was silenced. The present study, to the best of our knowledge, is the first to report the TRAP1-MPTP opening-mitochondrial apoptotic pathway in cardiomyocytes, which may provide a novel approach for extracellular acidosis treatment. Previous studies have shown that inhibiting MPTP opening can regulate mitochondrial morphology (35). Unexpectedly, specific MPTP opening inhibitor CysA did not significantly reversed the mitochondrial ultrastructure damage induced by TRAP1 silencing under conditions of extracellular acidosis. This may indicate that TRAP1 maintained mitochondrial ultrastructure in an MPTP-independent manner; however, further studies are required to elucidate the detailed mechanisms involved. In conclusion, the present study demonstrates that TRAP1 protects cardiomyocytes against extracellular acidification by regulating MPTP opening (Fig. 7).

\section{Acknowledgements}

Not applicable.

\section{Funding}

The present study was supported by the Science and Technology Planning Project of Guangzhou, China (grant no. 201604020119). 


\section{Availability of data and materials}

The datasets used and/or analysed in the present study are available from the corresponding author on reasonable request.

\section{Authors' contributions}

LZ contributed to the conception of the study, performed the majority of the experiments and wrote the manuscript. TZ, LL and XG designed the present study, interpreted the results, revised the manuscript and approved the final version of the manuscript. XZ collected the experimental data, performed the main statistical analysis and assisted with the revision of the manuscript. XL, JZ, YL and XG performed the CCK-8, apoptosis, ROS and MMP assays, respectively and assisted with the revision of the manuscript. All authors read and approved the final manuscript.

\section{Ethics approval and consent to participate}

Not applicable.

\section{Patient consent for publication}

Not applicable.

\section{Competing interests}

The authors declare that they have no competing interests.

\section{References}

1. Kraut JA and Madias NE: Metabolic acidosis: Pathophysiology, diagnosis and management. Nat Rev Nephrol 6: 274-285, 2010.

2. Kraut JA and Madias NE: Treatment of acute metabolic acidosis: A pathophysiologic approach. Nat Rev Nephrol 8: 589-601, 2012.

3. Teplinsky K, O'Toole M, Olman M, Walley KR and Wood LD: Effect of lactic acidosis on canine hemodynamics and left ventricular function. Am J Physiol 258: H1193-H1199, 1990.

4. Gunnerson KJ, Saul M, He S and Kellum JA: Lactate versus non-lactate metabolic acidosis: A retrospective outcome evaluation of critically ill patients. Crit Care 10: R22, 2006.

5. Mitchell JH, Wildenthal K and Johnson RJ Jr: The effects of acid-base disturbances on cardiovascular and pulmonary function. Kidney Int 1: 375-389, 1972.

6. Wagner CA, Imenez Silva PH and Bourgeois S: Molecular pathophysiology of acid-base disorders. Semin Nephrol 39: 340-352, 2019.

7. Masgras I, Ciscato F, Brunati AM, Tibaldi E, Indraccolo S, Curtarello M, Chiara F, Cannino G, Papaleo E, Lambrughi M, et al: Absence of neurofibromin induces an oncogenic metabolic switch via mitochondrial ERK-mediated phosphorylation of the chaperone TRAP1. Cell Rep 18: 659-672, 2017.

8. Lettini G, Sisinni L, Condelli V, Matassa DS, Simeon V, Maddalena F, Gemei M, Lopes E, Vita G, Del Vecchio L, et al: TRAP1 regulates stemness through Wnt/ $\beta$-catenin pathway in human colorectal carcinoma. Cell Death Differ 23: 1792-1803, 2016.

9. Xiang F, Huang YS, Shi XH and Zhang Q: Mitochondrial chaperone tumour necrosis factor receptor-associated protein 1 protects cardiomyocytes from hypoxic injury by regulating mitochondrial permeability transition pore opening. FEBS J 277: 1929-1938, 2010.

10. Yoshida S, Tsutsumi S, Muhlebach G, Sourbier C, Lee MJ, Lee S, Vartholomaiou E, Tatokoro M, Beebe K, Miyajima N, et al: Molecular chaperone TRAP1 regulates a metabolic switch between mitochondrial respiration and aerobic glycolysis. Proc Natl Acad Sci USA 110: E1604-E1612, 2013.
11. Chen JF, Wu QS, Xie YX, Si BL, Yang PP, Wang WY, Hua Q and He Q: TRAP1 ameliorates renal tubulointerstitial fibrosis in mice with unilateral ureteral obstruction by protecting renal tubular epithelial cell mitochondria. FASEB J 31: 4503-4514, 2017.

12. Lau AT, He QY and Chiu JF: A proteome analysis of the arsenite response in cultured lung cells: Evidence for in vitro oxidative stress-induced apoptosis. Biochem J 382: 641-650, 2004.

13. Palladino G, Notarangelo T, Pannone G,Piscazzi A, Lamacchia O, Sisinni L, Spagnoletti G, Toti P, Santoro A, Storto G, et al: TRAP1 regulates cell cycle and apoptosis in thyroid carcinoma cells. Endocr Relat Cancer 23: 699-709, 2016.

14. Tomecka E, Wojasinski M, Jastrzebska E, Chudy M, Ciach T and Brzozka Z: Poly(l-lactic Acid) and polyurethane nanofibers fabricated by solution blow spinning as potential substrates for cardiac cell culture. Mater Sci Eng C Mater Biol Appl 75: 305-316, 2017.

15. Bass JJ, Wilkinson DJ, Rankin D, Phillips BE, Szewczyk NJ, Smith K and Atherton PJ: An overview of technical considerations for Western blotting applications to physiological research. Scand J Med Sci Spor 27: 4-25, 2017.

16. Wang L, Feng Y, Xie X, Wu H, Su XN, Qi J, Xin W, Gao L, Zhang Y, Shah VH and Zhu Q: Neuropilin-1 aggravates liver cirrhosis by promoting angiogenesis via VEGFR2-dependent PI3K/Akt pathway in hepatic sinusoidal endothelial cells. EbioMedicine 43: 525-536, 2019.

17. Odell ID and Cook D: Immunofluorescence techniques. J Invest Dermatol 133: e4, 2013.

18. Kang T, Lu W, Xu W, Anderson L, Bacanamwo M, Thompson W, Chen YE and Liu D: MicroRNA-27 (miR-27) targets prohibitin and impairs adipocyte differentiation and mitochondrial function in human adipose-derived stem cells. J Biol Chem 288: 34394-34402, 2013.

19. Basit F, van Oppen LM, Schöckel L, Bossenbroek HM, van Emst-de Vries SE, Hermeling JC, Grefte S, Kopitz C, Heroult M, Hgm Willems P and Koopman WJ: Mitochondrial complex I inhibition triggers a mitophagy-dependent ROS increase leading to necroptosis and ferroptosis in melanoma cells. Cell Death Dis 8: e2716, 2017.

20. Xu Z, Lv XA, Dai Q, Lu M and Jin Z: Exogenous BDNF increases mitochondrial pCREB and alleviates neuronal metabolic defects following mechanical injury in a MPTP-dependent way. Mol Neurobiol 55: 3499-3512, 2018.

21. Hua G, Zhang Q and Fan Z: Heat shock protein 75 (TRAP1) antagonizes reactive oxygen species generation and protects cells from granzyme m-mediated apoptosis. J Biol Chem 282: 20553-20560, 2007.

22. Xu L, Voloboueva LA, Ouyang Y, Emery JF and Giffard RG: Overexpression of mitochondrial $\mathrm{Hsp} 70 / \mathrm{Hsp} 75$ in rat brain protects mitochondria, reduces oxidative stress, and protects from focal ischemia. J Cereb Blood Flow Metab 29: 365-374, 2009.

23. Zhang P, Lu Y, Yu D, Zhang D and Hu W: TRAP1 provides protection against myocardial ischemia-reperfusion injury by ameliorating mitochondrial dysfunction. Cell Physiol Biochem 36: 2072-2082, 2015.

24. Costantino E, Maddalena F, Calise S, Piscazzi A, Tirino V,Fersini A, Ambrosi A, Neri V, Esposito F and Landriscina M: TRAP1, a novel mitochondrial chaperone responsible for multi-drug resistance and protectionfrom apoptotis in humancolorectal carcinomacells. Cancer Lett 279: 39-46, 2009.

25. Tian X, Ma P, Sui CG, Meng FD, Li Y, Fu LY, Jiang T, Wang Y and Jiang YH: Suppression of tumor necrosis factor receptor-associated protein 1 expression induces inhibition of cell proliferation and tumor growth in human esophageal cancer cells. FEBS J 281: 2805-2819, 2014.

26. Zhang X, Zhong Z and Li W: Downregulation of TRAP1 aggravates injury of $\mathrm{H} 9 \mathrm{c} 2$ cardiomyocytes in a hyperglycemic state. Exp Ther Med 18: 2681-2686, 2019.

27. Teixeira J, Basit F, Swarts HG, Forkink M, Oliveira PJ, Willems PHGM and Koopman WJH: Extracellular acidification induces ROS- and mPTP-mediated death in HEK293 cells. Redox Biol 15: 394-404, 2018.

28. Wang YZ, Wang JJ, Huang Y, Liu F, Zeng WZ, Li Y, Xiong ZG, Zhu MX and Xu TL: Tissue acidosis induces neuronal necroptosis via ASICla channel independent of its ionic conduction. Elife 4: e05682, 2015.

29. Kwong JQ and Molkentin JD: Physiological and pathological roles of the mitochondrial permeability transition pore in the heart. Cell Metab 21: 206-214, 2015.

30. Bernardi P, Rasola A, Forte M and Lippe G: The mitochondrial permeability transition pore: Channel formation by F-ATP synthase, integration in signal transduction, and role in pathophysiology. Physiol Rev 95: 1111-1155, 2015. 
31. Rottenberg $\mathrm{H}$ and Hoek JB: The path from mitochondrial ROS to aging runs through the mitochondrial permeability transition pore. Aging Cell 16: 943-955, 2017.

32. Li X, Jia P, Huang Z, Liu S, Miao J, Guo Y, Wu N and Jia D: Lycopene protects against myocardial ischemia-reperfusion injury by inhibiting mitochondrial permeability transition pore opening. Drug Des Devel Ther 13: 2331-2342, 2019.

33. Sileikytė J, Devereaux J, de Jong J, Schiavone M, Jones K, Nilsen A, Bernardi P, Forte M and Cohen M: Second-generation inhibitors of the mitochondrial permeability transition pore with improved plasma stability. ChemMedChem 14: 1771-1782, 2019.

34. Panel M, Ruiz I, Brillet R, Lafdil F, Teixeira-Clerc F, Nguyen CT, Calderaro J, Gelin M, Allemand F, Guichou JF, et al: Small-molecule inhibitors of cyclophilins block opening of the mitochondrial permeability transition pore and protect mice from hepatic ischemia/reperfusion injury. Gastroenterology 157: 1368-1382, 2019.
35. Hom JR, Quintanilla RA, Hoffman DL, de Mesy Bentley KL, Molkentin JD, Sheu SS and Porter GA Jr: The permeability transition pore controls cardiac mitochondrial maturation and myocyte differentiation. Dev Cell 21: 469-478, 2011.

This work is licensed under a Creative Commons Attribution-NonCommercial-NoDerivatives 4.0 International (CC BY-NC-ND 4.0) License. 